\title{
Linguística I: uma experiência de ensino e aprendizagem baseada em atividades
}

\author{
Ricardo Joseh Lima \\ UERJ \\ Monique Débora Alves de Oliveira \\ UERJ
}

\begin{abstract}
Resumo
O ensino da disciplina Linguística I na graduação de Letras tem sido um desafio devido à carga de conceitos e informações teóricas a serem transmitidos para os alunos. Utilizando uma abordagem pedagógica que valorizou práticas em sala e a autonomia dos alunos em relação à aquisição do conhecimento, foi realizada uma experiência que se demonstrou bem sucedida em relação ao ensino de Linguística I. Este Relato apresenta as bases dessa abordagem, caracteriza as principais ações desenvolvidas na disciplina e enfatiza a necessidade de alteração de outros componentes do processo de ensino e aprendizagem, tais como a relação de afetividade entre professor e aluno e o ponto de vista avaliativo de desempenho. Espera-se, com isso, contribuir para uma discussão a respeito da reavaliação do papel de professores e alunos frente à questão das relações entre teoria e prática no ensino de Linguística.
\end{abstract}

Palavras-chave: Linguística; Abordagem centrada no aluno; Avaliação.

\begin{abstract}
Teaching an introductory course such as "Linguistics I" can be considered a difficult challenge owing to the heavy load of concepts and theoretical information to be transmitted to the students. This paper describes a successful experience in the teaching of "Linguistics I" which emphasized a pedagogical approach based on practical activities and on the autonomy of the students concerning their access to knowledge. This report presents the background to the approach, characterizes the main activities in the course, and emphasizes the need to change other components in the teachinglearning process, such as the affective relation between teacher and student and the evaluation of performance. This reflection will hopefully contribute to a discussion about a new assessment of the role of teacher and student concerning the question of the connection between theory and practice in the teaching of linguistics.
\end{abstract}

Keywords: Linguistics; Student centered approach; Assessment.

\section{INTRODUÇÃO}

No primeiro semestre de 2010, foi oferecida aos alunos de Letras de uma universidade pública estadual a disciplina eletiva "O Discurso Pedagógico", com o objetivo de se criar um espaço para reflexão sobre o ensino de Linguística na graduação. Concentrando-se na disciplina "Linguística I", professor e alunos se propuseram a 
discutir formas de concretizar os objetivos dessa disciplina, a saber, a apresentação e a fixação de correntes teóricas da Linguística e seus principais conceitos. Foi consenso que as questões que mais preocuparam giravam em torno da assimilação e apreensão das correntes teóricas. De modo geral, as orientações resultantes dessas discussões geraram um ponto de vista em que uma abordagem pedagógica centrada no professor cedia espaços para uma abordagem centrada no aluno (Barraket 2005). Três foram os principais pilares dessa mudança de foco: (1) a importância da realização de atividades em sala por parte dos alunos, (2) o privilégio da direção prática $\rightarrow$ teoria em relação aos objetivos de Linguística I e (3) a mudança de perspectiva no que diz respeito à avaliação dos conteúdos.

No segundo semestre de 2010, as propostas idealizadas pelos alunos foram concretizadas, com as devidas adaptações, na disciplina "Linguística I", turma 04. Este Relato de Experiência tem como objetivos expor como foi colocar na prática a mudança de abordagem pedagógica em seus três principais aspectos e fazer considerações a respeito dos resultados obtidos nessa disciplina. A primeira seção referente a esses aspectos descreve atividades e situações que aproximaram alunos, professor e monitora e possibilitaram deixar mais evidente a orientação do curso. A segunda seção traz ilustrações de atividades que privilegiaram aspectos práticos das correntes teóricas da Linguística. Na terceira seção, são descritos os mecanismos de avaliação dos alunos no curso em questão e, na quarta seção, considerações sobre o fazer pedagógico na universidade são levantadas e discutidas. Assim, afetividade, atividades e avaliação constituirão a base para a apresentação deste Relato de Experiência. Antes, no entanto, cabe inserir uma seção introdutória a respeito do curso de Linguística I, suas características e decisões que foram tomadas acerca da concretização das ideias expostas no parágrafo anterior.

\section{LINGUÍSTICA: O DESAFIO DA TEORIA E DA PRÁTICA}

A disciplina Linguística I é notadamente conhecida por professores e alunos do curso de Letras de uma universidade pública estadual como uma das mais desafiadoras do currículo. Isso acontece por vários motivos. Trata-se de uma disciplina que traz em seu conteúdo programático um amplo leque de correntes teóricas dessa ciência: o Estruturalismo, o Gerativismo, a Sociolinguística e correntes relacionadas à Análise do Discurso. 
A pesada quantidade que se pode antever, dado esse conteúdo programático, de conceitos, nomes e datas ainda não é o ponto mais problemático dessa disciplina. A inserção de discussões sobre conceitos teóricos e comparações entre as correntes é a causa do choque que os alunos ingressantes enfrentam. Despreparados para encarar uma torrente de informações teóricas, esses alunos estariam mais aptos a realizar atividades em que a prática fosse o elemento central, devido à faixa etária jovem e ao estímulo de estarem entrando em uma nova etapa de suas vidas.

Ainda assim, o curso que será descrito neste Relato de Experiência seguiu o conteúdo programático estabelecido. Desse modo, o curso teve como estrutura um momento de apresentação e acolhimento dos alunos, quatro momentos relacionados às correntes teóricas acima mencionadas e um momento de encerramento para avaliação e fechamento do curso. Cada momento referente às correntes teóricas obedeceu a uma mesma sequência didática, que compreendia seis aulas: inicialmente, uma atividade em que a participação dos alunos era central era apresentada; algumas discussões iniciais teóricas a respeito dessa atividade eram empreendidas; outra atividade era realizada e por fim novas discussões teóricas estendiam as conclusões obtidas nas atividades.

Nas próximas seções são relatadas situações bem sucedidas de cada uma das principais partes do curso, detalhando-se os passos para sua construção e fazendo referência aos resultados obtidos em cada uma dessas partes.

\section{O PRIMEIRO “A": AFETIVIDADE COMO COMPONENTE ESSENCIAL DA ATIVIDADE PEDAGÓGICA}

Um primeiro encontro sempre deixa marcas, como bem sabemos pelo ditado popular: "A primeira impressão é a que fica". Assim, também se pode considerar em relação ao primeiro dia de aula, que deve ser muito definidor do que vai acontecer ao longo do curso. Para tanto, deve-se proporcionar um clima de afetividade na relação professor/aluno e monitora (nesse caso específico), por meio da aproximação do aluno através de dinâmicas (Robinson \& Kakela 2006; Zigmond, 2008). O trabalho que foi feito em Linguística I será aqui apresentado do seguinte modo: uma descrição do primeiro dia de aula; um exemplo de atividade de aproximação e, por fim, um breve relato sobre o último dia de aula.

Para que todos pudessem se conhecer logo no primeiro dia de aula, plaquetas foram distribuídas à turma, nas quais os alunos deveriam preencher seu nome, em ambos os lados; dessa forma, todos poderiam revelar seus nomes, e também saber os de 
seus colegas. Nesse primeiro dia, foram feitas atividades que apresentavam o curso, mostravam seus objetivos e o modo como estes seriam abordados. Como o curso tinha por objetivo principal apresentar um novo olhar sobre antigos e novos objetos relativos à linguagem, uma das atividades feitas para revelar isso consistia em mostrar figuras com ilusões de ótica. A figura era apresentada, no PowerPoint, em tamanho pequeno, e era questionado aos alunos o que viam; a seguir, a mesma imagem era novamente mostrada, só que dessa vez ampliada de forma que a turma pudesse ver o que antes não era visto. Assim, eles viram, na prática, como seria o curso de Linguística I: teriam um novo olhar sobre estudos antigos que eles já conheciam sobre a linguagem e também tomariam conhecimento de novos estudos sobre a mesma.

Durante o curso, diversas atividades foram feitas para garantir a aproximação entre professor, alunos e monitora. Todas essas atividades foram elaboradas de modo que também cumprissem o objetivo principal do curso: mostrar um novo olhar sobre a forma como lidamos com a linguagem. Algumas dessas atividades foram bem marcantes tanto para os alunos, quanto para o professor e para a monitora. Entre elas, podemos citar o dia em que a aula aconteceu na Concha Acústica da Universidade (um espaço extra-sala (Robinson \& Kakela, 2006)), que ficou conhecida como "A aula da Concha". Naquela aula, o tema abordado foi "Língua e Linguagem": uma nova visão foi construída a partir da que eles traziam do Ensino Médio. Enquanto se podia ter de antemão algumas definições ("língua engloba linguagem", "linguagem é oral”, etc.), a atividade pretendeu que os alunos começassem "do zero" a apreensão desses termos. Imagens de várias situações comunicativas eram mostradas (animais, pessoas, sinais de trânsito, etc.) e os alunos iam classificando cada situação como sendo "língua" ou "linguagem". Houve bastantes divergências, o que ocasionou discussões e reflexões, um dos objetivos da aula. Ao final, os alunos descobriam que não havia somente uma definição de língua e de linguagem - e o segundo objetivo da aula foi atingido. Essa aula foi muito importante, pois permitiu, com o clima de descontração, que todos se conhecessem melhor: uma foto da turma foi tirada nesse dia, o que contribuiu para que as fisionomias associadas aos nomes fossem mais facilmente guardadas. Durante o curso, foi possível perceber pela forma com que professor, monitora e alunos se referiam a esse tipo de atividade, como estas tiveram um impacto afetivo sobre todos.

A última aula também foi organizada de forma que fosse diferente do padrão, que se constitui, em geral, da entrega das notas e de desejos de boas férias. Inspirados nas propostas de Uhl (2005), organizamos o seguinte roteiro para nosso dia de 
encerramento: entrega da notas, exibição de um vídeo de encerramento ${ }^{1}$ e um café da manhã de encerramento.

A cada aluno foi entregue uma folha que continha sua nota detalhada com comentários sobre a mesma e possibilidade de refazer algumas tarefas para aumentar essa nota. Dessa forma, o aluno teve uma visão ampla do seu desempenho durante o curso.

O vídeo de encerramento foi feito pelo professor e pela monitora e era dividido em duas partes: a primeira tinha por objetivo relembrar as aulas do curso e a outra, fazer agradecimentos. A primeira parte do vídeo trazia imagens que marcaram cada aula (da primeira à vigésima nona) e também um desenho da turma feito por uma das alunas do curso. A segunda parte continha o nome de cada aluno, pois eles fizeram o curso acontecer, e também os agradecimentos do professor e da monitora. A exibição do vídeo de encerramento foi um momento muito emocionante para todos os presentes: pudemos ver o quanto a relação professor/aluno/monitora foi aproximada e afetiva durante o curso.

A terceira e última parte do dia de encerramento foi o café da manhã, intitulado "Café com Linguística". Esse acontecimento foi divulgado pela monitora com semanas de antecedência. Todos contribuíram trazendo um item de uma lista de café da manhã que foi passada à turma. No dia, após a exibição do vídeo de encerramento, todos foram para uma sala, previamente organizada e decorada pela monitora, para a confraternização. Foi um momento de total descontração, no qual o fim de um curso construtivo foi celebrado por todos.

Esta seção tratou do tema afetividade e de modo coerente com essa característica, que é subjetiva, não apresentou resultados objetivos com valores ou aspecto quantitativo.

\section{O SEGUNDO "A": ATIVIDADES PRÁTICAS COMO BASE PARA INFORMAÇÕES TEÓRICAS}

A primeira discussão central da disciplina "O Discurso Pedagógico" (2010.1) focalizou os conteúdos de "Linguística I". Como apresentar a alunos recém-chegados ao curso de Letras um panorama das principais correntes teóricas da Linguística e seus conceitos? A resposta que, aos poucos, foi se revelando trouxe uma visão consensual

\footnotetext{
${ }^{1}$ Disponível em http://www.youtube.com/watch?v=hx1R99DAjhc.
} 
por parte dos alunos: informações teóricas não deveriam ser privilegiadas de modo descontextualizado; essas poderiam ser obtidas como resultado da realização de atividades com os alunos; por fim, dado o papel central do aluno na construção do conhecimento, um conjunto de informações teóricas não precisaria ser veiculado durante o curso, sendo sua obtenção responsabilidade do aluno (Hassel \& Lourey, 2004). A resposta acima pode ser resumida no seguinte raciocínio: as correntes teóricas utilizam-se de conceitos para produzir pesquisas e trabalhos práticos; o aluno assimilaria, por meio de atividades práticas, em primeiro lugar e de modo central, essas pesquisas e trabalhos; a partir daí, haveria momentos de reflexão que levariam aos conceitos teóricos, que apareceriam como resultado de uma atividade e não como informações soltas e sem justificativa. A título de exemplo, serão descritas duas atividades que compuseram a disciplina "Linguística I". Ambas são referentes ao Estruturalismo, a primeira corrente estudada no curso, tal como apresentado na primeira seção deste Relato de Experiência.

O Estruturalismo Norte-Americano é uma corrente da Linguística que privilegia análises estruturais de formas isoladas. Assim, pode eleger uma sentença simples como "O menino viu a menina com binóculos" para descrever suas estruturas subjacentes possíveis ou mesmo uma palavra como "revitalização", com a finalidade de investigar as relações entre suas partes (prefixo, radical e sufixos). Esse foco faz com que essa corrente leve em conta dados sincrônicos e uma visão de língua como um objeto que pode ser estudado livre de interferências sociais e contextuais. O que foi exposto acima são informações teóricas a respeito dessa corrente.

Seguindo as orientações já discutidas a respeito do lugar de informações teóricas em Linguística I, foi apresentada aos alunos uma atividade em que eles foram convidados a debater a seguinte questão “Existem línguas inferiores?”. Línguas "candidatas" a serem enquadradas como "inferiores" foram analisadas pelos alunos: uma língua indígena (o Quéchua), uma língua africana (o Swahili) e uma língua asiática (Orkhono-Yeniseyan). Dividida em grupos, a turma realizou análises de palavras, construções verbais e sentenças dessas línguas que revelaram que elas em nada devem em termos de complexidade: o Swahili possui uma estrutura que se assemelha à nossa mesóclise; o Quéchua possui uma que pode ser comparada com o possessivo do inglês e o Orkhono-Yeniseyan um sistema de caso comparável ao do latim. A partir daí, cada grupo ficou responsável por procurar informações concernentes ao Estruturalismo Norte-Americano, a corrente teórica da Linguística que se propôs a realizar esse tipo de 
tarefa. Buscas em sites, na biblioteca e a leitura de um texto sobre essa corrente forneceram conteúdos teóricos complementares à atividade. Os grupos tiveram autonomia para realizar essas tarefas e o retorno obtido na aula demonstrou que houve assimilação da ideia de que o curso estava privilegiando atividades de descoberta e de prática, e não assimilação de informações teóricas transmitidas por uma fonte, o professor, que as detém e cujo único objetivo é fazer com que os alunos também as detenham de algum modo.

Outra atividade da disciplina Linguística I focalizou as dicotomias saussurianas. Cinco situações foram elaboradas para que os alunos travassem contato com as dicotomias: dois deles foram convidados a contar uma estória a partir de um roteiro comum; a turma pôde comparar músicas de várias épocas tratando do mesmo tema; duas duplas deveriam tentar adivinhar o significado de uma palavra inventada pelo professor; dois grupos tiveram como tarefa registrar palavras relacionadas a "casamento"; por fim, duas duplas tiveram a oportunidade de reagrupar palavras, gerando várias sentenças. Cada situação descrita não apenas fez menção a uma dicotomia, mas, crucialmente, possibilitou aos alunos construir cada uma delas a partir de bases conhecidas por eles (estórias, músicas, competições). Assim, a primeira situação levou à dicotomia Língua x Fala, tendo como ponte a ideia de que uma mesma estrutura comum (a Língua) pode possuir concretizações distintas (a Fala). A segunda trouxe a dicotomia Sincronia x Diacronia, com a comparação de músicas de várias épocas (Diacronia) e a análise específica de cada uma (Sincronia). A terceira situação abordou a dicotomia Significante x Significado ao destacar que o som de uma palavra não é uma pista para seu sentido, uma vez que a relação entre som (Significante) e sentido (Significado) é arbitrária para Saussure. Por fim, a quarta e a quinta situações remeteram à dicotomia Paradigma x Sintagma: palavras relacionadas a "casamento" foram agrupadas (Paradigma); e os arranjos obtidos com as palavras da última atividade foram analisados a respeito de quais eram possíveis e quais não eram (Sintagma).

A segunda atividade descrita remeteu, uma vez mais, à abordagem que toma o aluno como elemento central para a aquisição do conhecimento. As dicotomias saussurianas não foram apresentadas a eles, mas descobertas por eles. O papel do professor foi o de proporcionar a organização das atividades de descoberta e, posteriormente, disponibilizar fontes formais de informação a respeito dos conteúdos adquiridos. 
As duas atividades descritas nesta seção ilustraram os procedimentos didáticos adotados durante o curso de Linguística I. A prioridade das atividades e das dinâmicas sobre conteúdos teóricos foi destacada ao mesmo tempo que se pôde perceber que esses não foram deixados de lado, uma vez que um espaço foi aberto para sua circulação entre os alunos.

\section{O TERCEIRO “A”: MODOS ALTERNATIVOS DE AVALIAÇÃO}

As duas seções anteriores procuraram demonstrar as diferenças entre uma abordagem tradicional e uma alternativa para o ensino de Linguística I na graduação de Letras. A parte de avaliação, por conseguinte, não poderia deixar de se enquadrar no que de mais essencial propõe a abordagem alternativa, que é a centralidade do aluno no processo de aprendizagem. Desse modo, uma estrutura de avaliação bastante comum (seminários com temas decididos pelo professor; prova individual e sem consulta com perguntas sobre vários tópicos da matéria, também preparadas pelo professor) foi deixada de lado e outro caminho foi escolhido para dar conta de se ter, ao final do curso, algo que se possa chamar de avaliação. Três foram as bases desse caminho: a valorização das atividades práticas, a utilização de um portfólio (Villas-Boas, 2004) e a observação da participação do aluno durante o curso.

A maioria das aulas do curso foi composta por atividades como as ilustradas na seção 3. Como havia atividades que mobilizavam a turma de diferentes modos (algumas vezes, a turma era dividida em dois grupos e outras vezes, em um número maior de grupos), essas foram recebendo "valores" distintos. Assim, por exemplo, a atividade descrita sobre o Estruturalismo Norte-Americano valeu 2,0 pontos; já a elaboração de um vídeo de um minuto sobre Preconceito Linguístico, parte do conteúdo de Sociolinguística, valeu 1,5. A realização bem sucedida de uma atividade conferia ao aluno seu valor integral. Entendeu-se como "bem sucedida" uma atividade em que houve participação efetiva dos alunos, com interações, e concluída com seus objetivos atingidos. Os valores obtidos com participação nas atividades em sala corresponderam a $45 \%$ da média final. Esse percentual é o mais alto das três bases da avaliação e, portanto, indica que habilidades participativas, presença em sala e interesse em realizar uma atividade completa foram considerados como tópicos relevantes para o curso.

A utilização de um portfólio pelos alunos revelou-se um desafio para o professor e para a monitora na medida em que era necessário ler os registros de cada aula de cada 
um dos vinte e seis alunos do curso. No entanto, depoimentos espontâneos (como ““‘ $E$ incrível como o portfólio está salvando a vida de todos nós!" foi a frase que eu mais ouvi. Haha") demonstraram que a proposta foi aceita pela turma com satisfação. Como cada aluno, assim como o professor e a monitora, possuía seu próprio portfólio (em formato PowerPoint), foi possível a eles personalizar e reconhecer como "seu" aquele material. O portfólio era constituído de duas partes: um Diário de Bordo, em que o aluno deveria registrar, mesmo de modo informal, as impressões de cada aula e um espaço denominado "Meus Textos", em que, periodicamente, o aluno era convidado a escrever um texto de modo formal sobre um dos conteúdos do curso. O objetivo dessa segunda parte foi o de demonstrar para alunos recém-chegados à universidade a importância do domínio de uma linguagem acadêmica. No lugar de provas, que punem os que não conseguem assimilar de imediato essa importância, os Meus Textos foram considerados como etapas na construção da assimilação dessa importância. Nenhuma das duas partes foi valorada quantitativamente pelo modo tradicional (ou seja, notas). Critérios de adequação das duas partes foram discutidos com os alunos e, no final, um valor (que fatalmente se transformaria em uma nota...) foi atribuído a cada parte. $\mathrm{O}$ portfólio correspondeu a $40 \%$ da média final.

Por fim, $15 \%$ da média final foi atribuído à assiduidade do aluno no curso. Essa pode ser uma das razões da alta taxa de presença dos alunos em sala $(86,9 \%$ na média de vinte e cinco aulas). No entanto, há motivos para suspeitar que possa não ter sido a única. Em duas aulas, houve 100\% de presença dos alunos: em uma não havia qualquer atividade de participação em jogo; na outra, embora houvesse uma atividade, o fato de ter sido no final do semestre letivo pode ser visto como um indicador de que a turma "comprou a ideia" do curso, participando ativamente e encaminhando um final de curso que eles encaravam como prazeroso.

A afirmação que fechou o parágrafo anterior deve ser encarada com muita cautela, uma vez que a voz que caracteriza, neste artigo, o que os alunos pensaram do curso não é a deles, mas a do professor e a da monitora. No entanto, à alta taxa de presença nas aulas vem se somar uma avaliação anônima que os alunos fizeram do curso, atribuindo notas à Estruturação do Curso (média 9,6), Didática do Professor (média 9,3), Interesse pela Disciplina (média 9,3) e Avaliações (média 7,9), o que gerou uma média de 9,0 para o curso. A média mais baixa, de Avaliações, se deveu ao fato de os alunos terem ficado inseguros com uma abordagem não quantitativa durante o curso em relação à nota. No entanto, na aula final, foi dada a possibilidade de cada aluno rever 
sua nota e atribuir uma distinta a que o professor tinha atribuído. Essa possibilidade não foi utilizada de modo significativo pelos alunos, o que pode revelar seu grau de satisfação com o resultado final obtido no curso.

\section{CONSIDERAÇÕES FINAIS}

Este Relato de Experiência apresentou uma experiência de ensino e aprendizagem de Linguística na graduação de Letras que se diferenciou de outras por ter se concentrado em atividades nas quais a participação do aluno era um elemento central. Com isso, foi possível criar um ambiente em que "fazer" Linguística pudesse levar a “pensar" Linguística. A aproximação com a Linguística pela via do "fazer" tornou os alunos mais receptivos a essa disciplina, posto que se tornaram, em muitos momentos do curso, senhores do percurso de aquisição de habilidades e conhecimentos linguísticos.

A opção por deixar a cargo dos alunos a responsabilidade de acessar conteúdos e conceitos teóricos pode ser considerada de risco, ainda mais que a referida disciplina talvez seja a única oportunidade que eles têm de entrar em contato de modo formal com esses conteúdos e conceitos. No entanto, a visão de que as fontes de conhecimento não se restringem mais ao espaço da instituição Escola no século vinte e um e de que essa instituição deve ser agora o espaço de reflexão e crítica do conhecimento (Roettger et al. 2007) foi utilizada como base para a construção do curso. Os depoimentos espontâneos e anônimos dos alunos ao final do curso ${ }^{2}$ são indicadores de que esse é um caminho que vale a pena ser explorado mais vezes e com mais profundidade.

\section{REFERÊNCIAS}

Barraket, J. (2005). Teaching research method using a student-centred approach? Critical reflections on practice. Journal of University Teaching \& Learning Practice 2 (2), 63-74.

Hassel, H. \& Lourey, J. (2004). The dea(r)th of student responsibility. College Teaching 53 (1), 2-13.

\footnotetext{
2 "Linguística I, eterna por sua essência”, "Linguística 1: novos olhares sobre temas já conhecidos, descobertas, maneiras diferentes de aprender, e, por que não, respeito ao próximo", "Uma matéria diferente pois faz o aluno pensar para entender e não decorar" e "No final, eu lembrava de todos os conceitos" são alguns desses depoimentos.
} 
Robinson, C. \& Kakela, P. (2006). Creating a space to learn: a classroom of fun, interaction, and trust. College Teaching 54 (1), 202-206.

Roettger, C. et al. (2007). Teaching: more than just lecturing. Journal of University Teaching \& Learning Practice 4 (2), 119-133.

Uhl, C. (2005). The last class. College Teaching 53 (4), 165-166.

Villas-Boas, B. (2004). Portfólio, avaliação e trabalho pedagógico. Campinas, SP: Papirus.

Zigmond, R. (2008). Ask a provocative question to break the ice. College Teaching 56 (3), 154-155.

\section{OS AUTORES}

Ricardo Joseh Lima é Doutor em Linguística, pela Universidade Federal do Rio de Janeiro e Professor Adjunto da Universidade do Estado do Rio de Janeiro. Coordena um Programa de Extensão e orienta alunos de graduação e pós-graduação. Tem se interessado recentemente por questões relativas ao ensino de Linguística na graduação.

E-mail: rilimauerj@gmail.com

Monique Débora Alves de Oliveira é graduanda em Letras-Português/Literaturas, na Universidade do Estado do Rio de Janeiro. Tem bolsa de monitoria de Linguística I na mesma Universidade. Também tem interesse por questões relativas ao combate ao Preconceito Linguístico nas escolas.

E-mail: $\underline{\text { mnqdbr@gmail.com }}$ 